\title{
Resumen
}

La llegada de las maras era una de las principales amenazas vinculadas con la aparición de las primeras bandas juveniles de origen americano en España, a mediados de la década del 2000. Los niveles de violencia y la actividad delictiva que Ilevaban a cabo en América Central y del Norte, junto a informaciones acerca de su voluntad de expandirse por Europa, así lo confirmaban. La vistosidad de algunos de sus miembros así como sus niveles de violencia han hecho que los medios de comunicación les prestaran una especial atención, transmitiendo un mensaje, en muchos casos, alarmista y sensacionalista.

\section{La llegada de las maras a Cataluña}

Policía de la Generalitat - Mossos d'Esquadra, España sherrero@gencat.cat

Recibido: marzo 24 de 2015 Aceptado: mayo 11 de 2015

No obstante, con el paso del tiempo este riesgo no se ha llegado a concretar en toda su extensión. Tanto la Mara Salvatrucha como el Barrio 18 han Ilegado, sí, pero lejos de apropiarse del territorio, sembrar la violencia y replicar sus prácticas delictivas en el lado europeo del Atlántico, su actividad ha podido ser controlada y no han llegado a suponer el grave problema social o criminal que se podía prever.

\section{Palabras clave}

Maras, pandillas, Cataluña, España, policía, medios de comunicación. 


\section{Abstract:}

The "Maras" arrival was one of the main threats linked to the presence of the first youth gangs of American origin in Spain during the mid 2000's. The levels of violence, as well as the criminal activity they were involved in throughout Northern and Central America, as well as their well publicized intent to expand throughout Europe seemed to be finally confirmed. The shocking nature of some of their members, as well as the levels of extreme violence which have been displayed by Maras, have managed to lock the attention of the media outlets who have in turn bestowed upon them a special attention, that in the majority of cases has been translated into alarmist and sensationalist messages.

The arrival of "Maras" into Cataluña

Santiago Herrero Blanco

Policía de la Generalitat - Mossos d'Esquadra, España sherrero@gencat.cat

Received: march 24 de 2015 Accepted: may 11,2015

BIBLID [2225.5648 (2015), 5:1, 75.102]
Nonetheless, over the course of time this risk does not seem to have truly reached its estimated potential. Both Mara Salvatrucha as well as Barrio 18 did indeed arrive, but far from taking over the territory, sowing violence and replicating their criminal conduct on Europe's side of the Atlantic, the authorities have been able to curb their activities and they've yet to become the critical social or criminal crisis that was originally expected.

\section{Key words:}

Maras, gangs, Cataluña, España, police, media outlets 


\section{Introducción ${ }^{1}$}

Tres años atrás se publicó en esta misma revista el artículo "Pandillas en Cataluña: el abordaje desde la Policía de la Generalitat - Mossos d'Esquadra" (Herrero, 2012), en el cual se realizaba un acercamiento al fenómeno de los grupos juveniles en esta comunidad española. Los apartados principales eran la evolución del fenómeno y de pandillas como Latin Kings, Ñetas, Black Panthers, Trinitarios, Mara Salvatrucha y Barrio 18, y cómo se había abordado el fenómeno desde el ámbito policial. Se destacaba también que la aparición de Latin Kings y Ñetas era posterior a la primera llegada de un flujo de migrantes ecuatorianos y la de Black Panthers y Trinitarios, a la de migrantes dominicanos. El presente artículo es una continuación de aquel, dejando de lado el abordaje policial y centrando el foco de atención en dos grupos en concreto, la Mara Salvatrucha (MS) y el Barrio 18 (B18).

Nuevamente es necesaria una contextualización sobre los flujos migratorios registrados en Cataluña en los últimos años, en este caso, haciendo énfasis en los migrantes centroamericanos. A partir de aquí se centrará la atención en la aparición y evolución de ambos grupos pandilleriles en dicha comunidad. Además, se ofrecerá alguna pincelada sobre estos en el resto de España y en otros países europeos. Antes de finalizar con unas reflexiones personales del autor, se aborda el tratamiento que los medios de comunicación han hecho sobre estos grupos en concreto.

\section{Metodología}

La base principal del artículo ha sido la experiencia profesional y personal del autor, que, entre los años 2004 y 2012, trabajó en el seguimiento y análisis de estos grupos en Cataluña (hasta el año 2006 en el Área Central de Análisis Estratégico -ACAE- de la Policia de la Generalitat . Mossos d'Esquadra y, desde entonces, en el Gabinete de Seguridad del Departamento de Interior, en el que sigue destinado, aunque actualmente con otras responsabilidades). No obstante, el autor ha mantenido su interés académico sobre los fenómenos de delincuencia juvenil grupal, y no ha dejado de seguir las novedades que al respecto aparecían tanto en medios de comunicación como en el ámbito académico.

Para la elaboración del contexto demográfico se han buscado y seleccionado datos del Instituto de Estadística de Cataluña (Idescat). La información relativa a las maras en Cataluña (número de miembros, grupos formados,

$1 \quad$ El autor quiere agradecer y reconocer el trabajo realizado durante estos años por todos los miembros de la Policia de la Generalitat - Mossos d'Esquadra destinados en las diferentes unidades que han realizado el seguimiento de los grupos juveniles (en muchos casos remando a contracorriente). Buena parte de la información plasmada a continuación es fruto del trabajo de todos ellos. Mención especial merecen Lluís, por su confianza y sus enseñanzas; Xavi, por su pasión y dedicación; y David y Pilar, por su paciencia, compañerismo y resiliencia. 
hechos delictivos, etc.) se ha recuperado, sistematizado y contrastado con memorias, informes y diligencias policiales. También se han consultado archivos y recopilaciones de noticias elaboradas por la ACAE y el Gabinete de Seguridad, y fotografías obtenidas o recibidas por estas unidades durante la época de seguimiento del fenómeno. Los actuales responsables de la investigación de estos grupos también han colaborado facilitando datos sobre la situación actual. Para el apartado correspondiente al resto de España, se ha recuperado información de la base de datos del poder judicial, de medios de comunicación, además de la información obtenida de fuentes académicas referidas en la bibliografía. La información sobre Italia ha sido obtenida a través de búsquedas de internet y con la colaboración de Luca Queirolo Palmas (2013).

\section{Contexto demográfico}

Como ya se ha expuesto en el segundo número de esta revista (Herrero Blanco, 2012), y como se puede comprobar en el gráfico 1, la población residente en Cataluña aumentó de manera considerable durante la primera década del siglo XXI, en gran medida al recibir una destacada cantidad de inmigrantes, en edad productiva y reproductiva ${ }^{2}$ (lo que también contribuyó a aumentar las tasas de natalidad del 10.2 del año 2000 al máximo de 12.1 en el año 2008 [Idescat, 2015a]). Así, mientras la población del año 2000 era de 6,261,999 habitantes, de los cuales 181,590 eran extranjeros, en el año 2014 la población era de 7,518,903, con 1,089,214 de extranjeros. Esto ha supuesto pasar de un porcentaje de $2.90 \%$ de ciudadanos extranjeros al 14.49 \% (la tasa máxima se había alcanzado en 2009 con $15.91 \%$ ).

El crecimiento demográfico fue considerable hasta 2009, y en los tres años siguientes la cifra de ciudadanos extranjeros se mantuvo estable. A partir de 2012, parece haberse iniciado un leve descenso demográfico; por una parte, debido al retorno de personas inmigradas a sus países de origen y, por otra, por la emigración de ciudadanos catalanes a otros países (pasaron de 185,848 en 2009 a 221,444 en 2014 [Idescat, 2011]). En este contexto, también se ha producido la nacionalización de ciudadanos extranjeros que llevan un tiempo residiendo en Cataluña o en otras partes de España. Especialmente por este saldo migratorio negativo, Cataluña perdió 17,258 habitantes en 2013 y 34,747 en 2014. Este descenso está motivado por el descenso de población extranjera, que fue de 28,307 personas en 2013 y de 69,258 en 2014 (Idescat, 2015b).

2 Según datos del Instituto de Estadística de Cataluña (Idescat, 2015b), de las 181,590 personas extranjeras que residían en Cataluña el año 2000, el $55 \%$ tenían entre 20 y 44 años. En 2009, de $1,189,279$ personas extranjeras, el $63 \%$ tenían entre 20 y 44 años. 


\section{Gráfico 1 \\ Crecimiento demográfico en Cataluña}

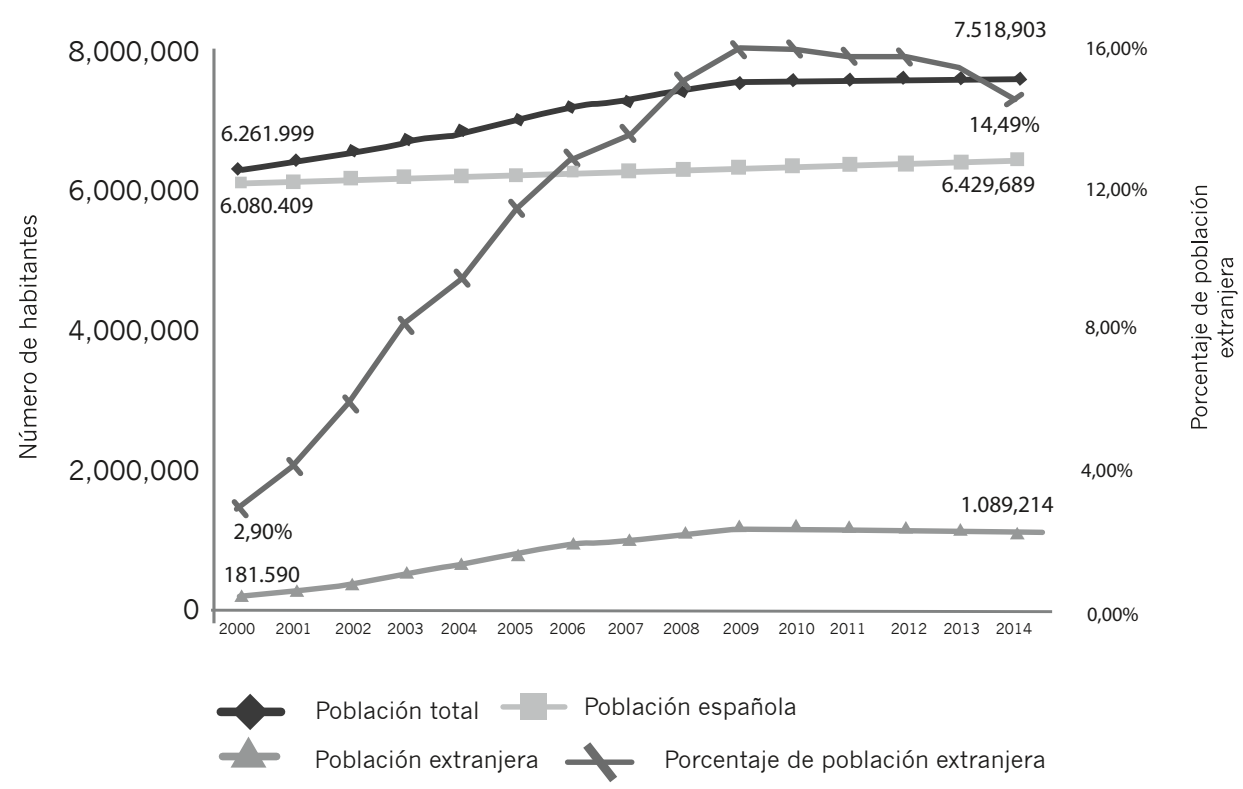

Fuente: Instituto de Estadística de Cataluña. Padrón continuo. Datos a 1 de enero de cada año.

Esta disminución presenta algunos matices que considerar, ya que mientras las tendencias de los ciudadanos europeos y africanos han sido bastante estables, con leves oscilaciones, el descenso de ciudadanos americanos ha sido prácticamente continuado entre 2009 y 2014, con un leve repunte en 2012. Esto ha provocado que, el colectivo americano (mayoritariamente sudamericano), pasara de ser el más numeroso en 2009, el $34 \%$ del total de extranjeros, a ser el tercero en 2014, con el $26 \%$ del total de extranjeros.

Esta tendencia a la baja se ha centrado especialmente en el colectivo sudamericano, que han pasado de estar formado por más de 344,000 personas a ser de poco más de 221,000. Así, en 2009, representaba el $85 \%$ del total de americanos residentes en Cataluña, mientras en 2014 han sido el $76 \%$. El colectivo caribeño se ha mantenido estable, aunque con alguna oscilación entre los 30,000 y los 33,000 habitantes, y, por el contrario, los centroamericanos han tenido un crecimiento del $28 \%$ en estos cinco años, y han pasado de 25,000 a casi 33,000 , de manera que han superado a los caribeños como segundo grupo más numeroso entre los americanos. 


\section{Gráfico 2}

\section{Población extranjera en Cataluña, de 2009 a 2014}
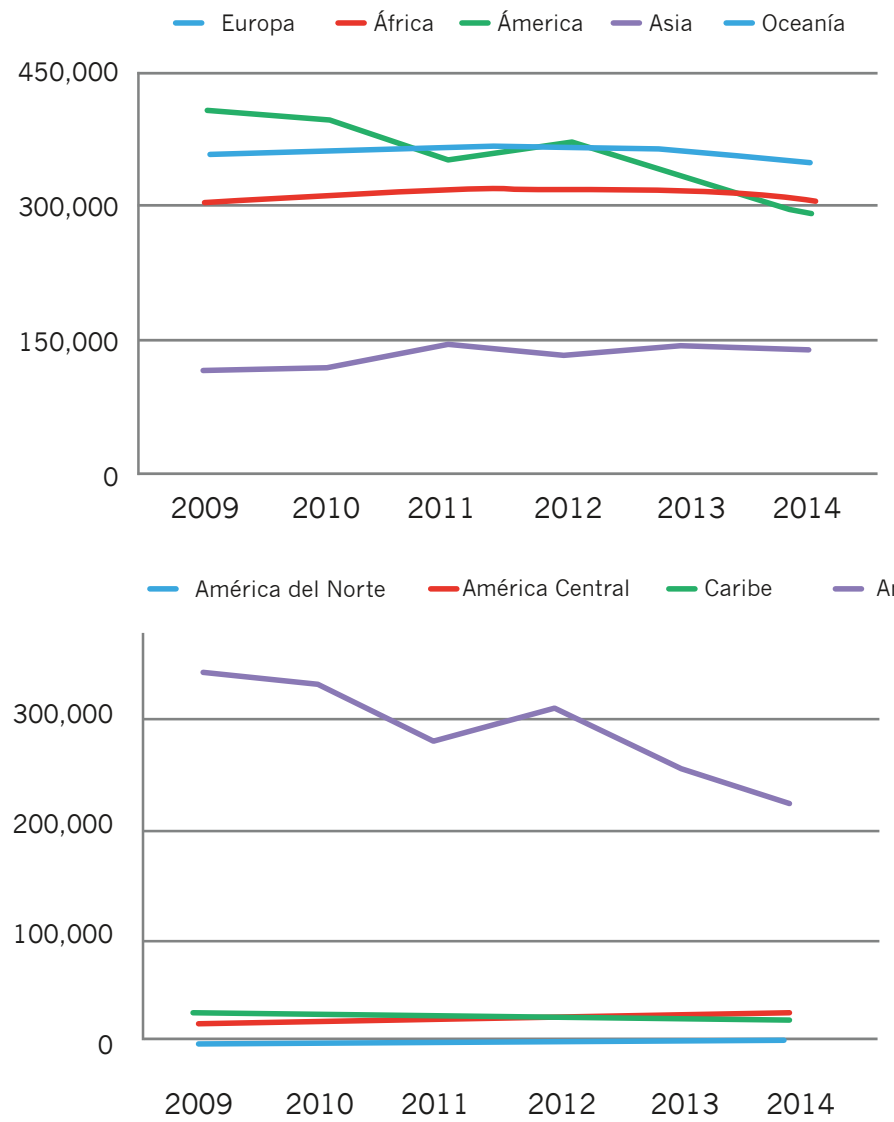

Fuente: Instituto de Estadística de Cataluña. Datos a 1 de enero de cada año.

Las diferencias también son significativas entre países. Así, entre los países de América Central, como se ve en el gráfico 3, destacan especialmente las poblaciones hondureña y mexicana. En el año 2000, casi la mitad de los 2400 centroamericanos que residían en Cataluña eran mexicanos, seguidos, a gran distancia, por hondureños y salvadoreños (479 y 455 respectivamente). La población mexicana fue creciendo de manera más o menos continua hasta el 2006, año en que prácticamente llegó a los 9000 residentes en Cataluña, pero durante ese año se produjo un considerable cambio de la tendencia, ya que en el 2007 bajó hasta poco más de 7,000 habitantes. Durante los años siguientes, esta población tuvo algunas oscilaciones alrededor de los 7,500 habitantes, y en el último año ha vuelto 
a tener un importante descenso. Por el contrario, la población hondureña residente en Cataluña ha ido aumentando de manera continua y destacada, llegando, el año 2014 a más de 20,000. La población salvadoreña en Cataluña también ha experimentado un crecimiento, aunque mucho más moderado que el de la hondureña, ya que en el año 2014 era de 2325 ciudadanos.

Una característica común es la feminización de la población centroamericana residente en Cataluña, ya que las mujeres son el $67 \%$, porcentaje más acentuado en el colectivo hondureño (el $71 \%$ de mujeres por un $29 \%$ de hombres), y la concentración en las franjas entre los 20 y los 39 años (Idescat, 2015b).

\section{Gráfico 3}

Población extranjera por país, de 2000 a 2014

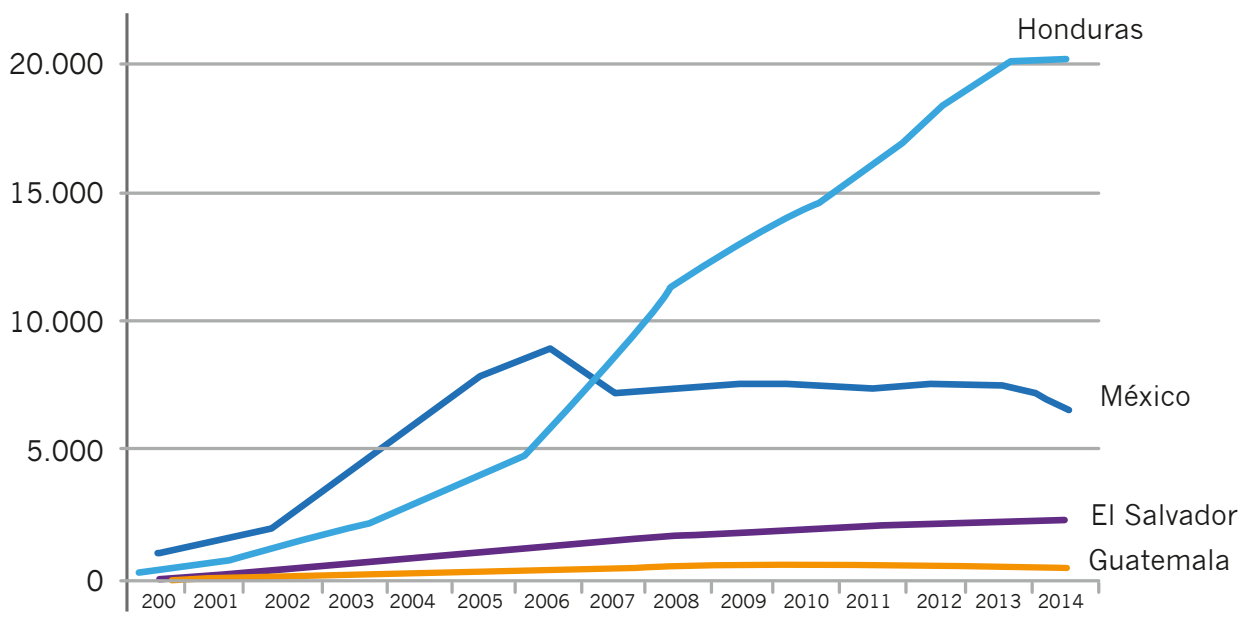

Fuente: Instituto de Estadística de Cataluña. Población extranjera. Datos a 1 de enero de cada año. 


\section{Maras en Cataluña}

\subsection{Primeros mareros}

La llegada a Cataluña de grupos juveniles, bandas o pandillas, vinculadas con otros grupos del continente americano, se produce a principios de la década del 2000. Entre finales del año 2002 y principios de 2003 se realizan los primeros informes policiales sobre la presencia de Latin Kings en las ciudades de Barcelona y l'Hospitalet de Llobregat. En el año 2003 también se detectan los primeros grupos de Ñetas. En ambos casos, entre los primeros miembros de cada uno de los grupos había una amplia representación de jóvenes ecuatorianos (especialmente de la ciudad de Guayaquil) que, mayoritariamente, o bien ya habían formado parte de estos grupos en su país de origen, o bien conocían de su existencia y sus dinámicas. Por este vínculo con Ecuador, en Cataluña se reproduce la rivalidad entre ambos grupos. La gran Ilegada de ciudadanos ecuatorianos favoreció el crecimiento inicial de ambos grupos a los que, rápidamente, se incorporaron jóvenes de otras nacionalidades; inicialmente latinoamericanas y, con el paso del tiempo, también españoles o jóvenes de otros orígenes.

Las primeras indagaciones policiales sobre estos grupos y sobre el fenómeno de las pandillas evidenciaron las diferentes realidades de los gangs de los Estados Unidos y las pandillas o naciones en América Latina. Dentro de este universo de grupos juveniles, se prestó especial atención a las maras que, tanto en América Central como en los Estados Unidos, representaban un riesgo superior por sus mayores niveles de violencia (Red para la Infancia y la Adolescencia de El Salvador, 2004; Pardo, 2004).

Por esta razón, la aparición en el año 2004 de un grupo que se identificaba con la Mara Salvatrucha (MS) no pasó desapercibida entre los pocos policías que, en aquel momento, ya trabajaban en Cataluña sobre grupos juveniles.

Los primeros indicios detectados vinieron por miembros de otros grupos que empezaron a nombrar a la Mara Salvatrucha en un barrio de Barcelona. Este grupo inicialmente estaría formado por una treintena de miembros de nacionalidades diversas: algún centroamericano, si bien la mayoría eran de otros países latinoamericanos, así como españoles y filipinos.

Las primeras informaciones se empezaron a contrastar con la detección en las cercanías de su lugar de reunión de dos pintadas con las letras "MS". Una de ellas tenía, en el interior de la S, tres puntos que formaban un triángulo. Además, entre ambas pintadas había una tercera que representaba una mano con los dedos índice y meñique levantados, simbolizando unos cuernos. Estas pintadas representaban simbología 
identificada con este grupo, aunque ni el tipo de letra ni el dibujo de la mano se parecían excesivamente al tipo de imágenes vistas. Más adelante, también se detectaron otras pintadas o grafitis en los alrededores del lugar inicialmente localizado como su punto de reunión, entre ellas en una parada de metro (suburbano).

\section{Foto 1. Primeras pintadas de la Mara Salvatrucha aparecidas} en Barcelona

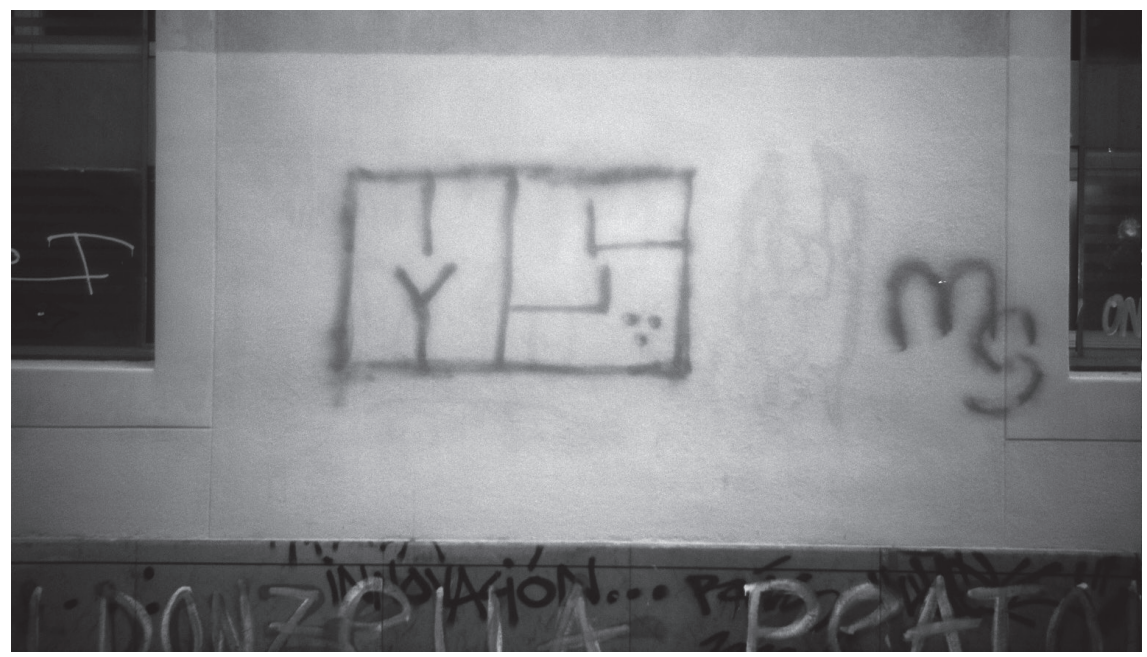

Fuente: Archivo Gabinet de Seguretat

Fotos 2 y 3. Pintadas de la Mara Salvatrucha en el metro de Barcelona
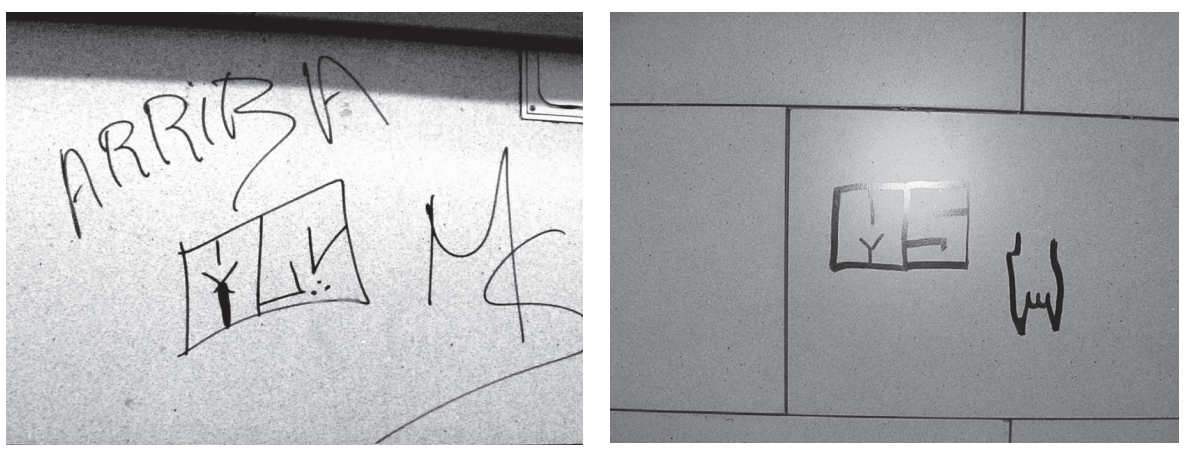

Fuente: Archivo Gabinet de Seguretat 
La conflictividad de este grupo fue inicialmente baja. Durante los primeros meses, la Policía apenas tuvo constancia de su participación en alguna pelea (una de ellas se produjo cuando dos miembros de este grupo se acercaron al lugar donde se estaba realizando una reunión de Latin Kings), y la mayor parte de incidentes tenían que ver con la actividad delictiva individual por parte de sus miembros sin aparente relación con la dinámica grupal.

Además, el grupo ya se había hecho presente en internet y se habían detectado algunos mensajes en foros (entre otros en varios hilos de conversación del foro LoQUo) ${ }^{3}$, en que los usuarios mencionaban la existencia de la Mara Salvatrucha en Barcelona.

El primer incidente destacado de este grupo sucedió en marzo de 2005, cuando se produjo una pelea tumultuaria en el interior de una hamburguesería del centro de Barcelona, en la cual resultaron heridos dos jóvenes y una empleada del local. Esta pelea fue precedida por algunos enfrentamientos previos en el entorno de una discoteca cercana. En los días posteriores, aumentó la actividad en el foro de internet LoQUo, en el que ya se había detectado la participación de miembros de diversos grupos juveniles, llegando a manifestar algunos de los usuarios de este espacio que los agresores habían sido miembros de la Mara Salvatrucha que, junto con miembros de Ñetas, habían atacado a unos Latin Kings ${ }^{4}$. A partir de este momento, los mensajes intercambiados por internet fueron subiendo de intensidad y se llegó a hablar de la existencia de alguna arma de fuego, extremo que no se pudo constatar. En los alrededores de las zonas de reunión de estos grupos en el centro de Barcelona también fueron frecuentes las pintadas y grafitis que evidenciaban la rivalidad de la Mara Salvatrucha y los Ñetas con los Latin Kings.

La actividad de este grupo quedó rápidamente truncada. En abril de ese mismo año, la Policía detuvo a ocho de sus miembros por robar con violencia a usuarios del metro de Barcelona. En uno de estos robos, un pasajero que intentó defender a una de las víctimas fue agredido con piedras que los agresores habían cogido bajando a las vías del metro ("Detenidos ocho", 2005). Aunque los medios de comunicación inicialmente atribuyeron estos hechos a un grupo de Latin Kings, indagaciones policiales constataron que las personas detenidas, de varias nacionalidades, pertenecían al grupo de la Mara Salvatrucha.

3 El foro LoQUo (http://foro.loquo.com) finalizó su actividad y las páginas ya no están disponibles en internet.

4 Los mensajes se habían dejado en varios hilos de conversación, entre otros en http://foro.loquo.com/ viewetopic. php?t=2125\&postdays=0\&postorder=asc\&start=1410. Dicho foro finalizó su actividad y las páginas ya no están disponibles en internet. 
Después de estas detenciones, cesó la actividad de este grupo de la Mara Salvatrucha.

Pese a que la violencia empleada en sus actividades fue superior a la habitual en otros grupos en aquellos momentos, un claro ejemplo fue la agresión del metro, y pese a que se identificaba bajo el nombre de Mara Salvatrucha, esta primera formación presente en Cataluña no se consideró que tuviera vínculos con la MS centroamericana. Por ese motivo, en ocasiones se ha hecho referencia a aquel primer grupo como pseudomaras, para diferenciarlos de las maras propiamente dichas.

\subsection{La aparición del Barrio 18}

En el año 2007, también se empieza a notar, por primera vez, la presencia del Barrio 18, en este caso, en la ciudad de Girona. A partir de la investigación de un robo con violencia ocurrido a mediados de ese año, el denunciante declara que un grupo numeroso de personas se reúnen en un barrio de esta ciudad y quieren marcar un territorio, amenazando, coaccionando e intimidando a los vecinos que pasan por la zona. Además de la utilización de objetos contundentes (bates de béisbol, cadenas, cinturones, etc.), también refieren la existencia de chimbas, armas de fuego fabricadas manualmente, que entre ellos se llaman homeboy o cholo. Los supuestos miembros de este grupo en su mayoría eran hondureños, además había algún salvadoreño y algunos de otras nacionalidades.

Pese a esa identificación previa del grupo, que se había formado en el año 2006, no se pudo evitar un homicidio, el hecho más grave causado por el Barrio 18 en Cataluña.

La noche del 13 de enero de 2007, se produjo una discusión en una discoteca de la ciudad de Girona, entre un joven estadounidense de origen dominicano y otro hondureño. Unas horas más tarde, todavía de madrugada, el joven estadounidense estaba en la calle, en la parte de atrás de la discoteca, cuando pasaron por allí, en un coche, el joven hondureño y unos compañeros. Detuvieron el vehículo a su lado y, sin bajar de él, efectuaron un disparo que, horas más tarde, acabaría con su vida. Los atacantes huyeron del lugar y se deshicieron del arma. 
Foto 4. Arma utilizada en el homicidio

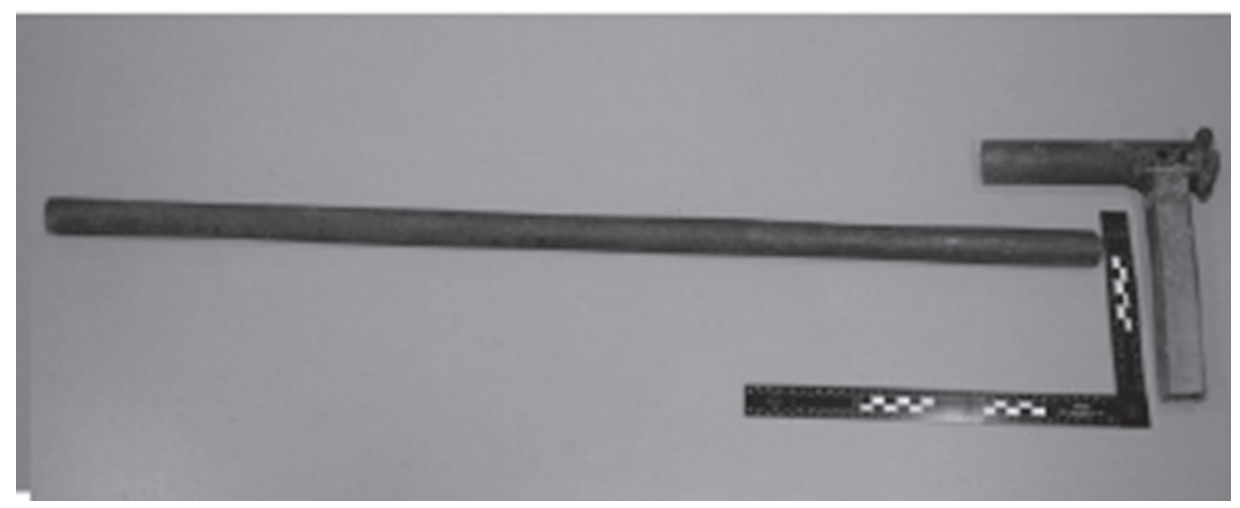

Fuente: Policia de la Generalitat - Mossos d'Esquadra

Los autores de los hechos fueron detenidos en unas horas y el arma, recuperada. Se trataba de una chimba cuyas partes dejaron los autores en dos lugares distintos. Dos piezas de hierro, la primera formada por un tubo cilíndrico soldado con otro octogonal y la segunda, por un tubo largo de hierro de $91 \mathrm{~cm}$ de largo por $2 \mathrm{~cm}$ de diámetro.

En la investigación de los hechos se supo que la víctima había sido amenazada por el autor con un arma de fuego; además, el autor del disparo había sido identificado como uno de los miembros del posible grupo del Barrio 18.

En el barrio donde se reunía el grupo de hondureños, se encontraron pintadas claramente relacionadas con esta pandilla, como se ve en la foto 5: números 18 de grandes dimensiones, XV3, "Diesiocho", The Barrio 18, $18 \mathrm{ST}$, e incluso el dibujo de un marero.

\section{Foto 5. Pintadas localizadas en uno de los puntos de reunión del Barrio} 18 en Girona

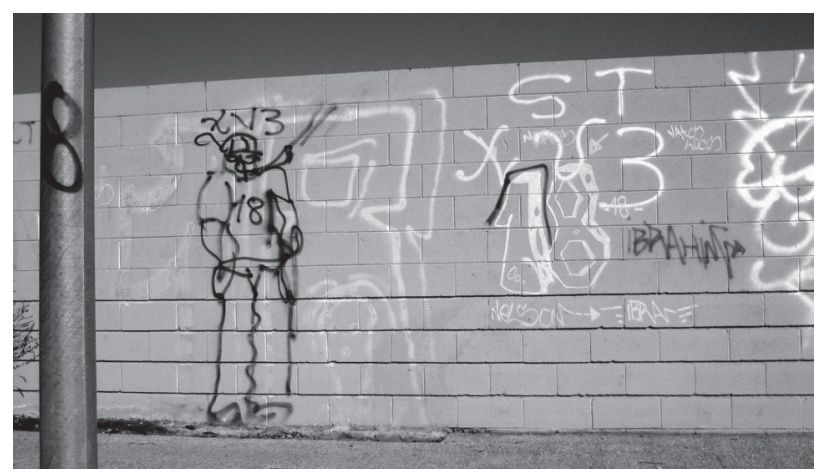

Fuente: Archivo Gabinet de Seguretat 
Para acabar de confirmar la relación de este grupo con el Barrio 18, el autor del disparo aparece en la foto de la reseña policial haciendo con su mano un símbolo de este grupo, como se aprecia en la foto 6.

\section{Foto 6. \\ Detalle de la fotografía del detenido por asesinato, haciendo el símbolo de Barrio 18 con la mano}

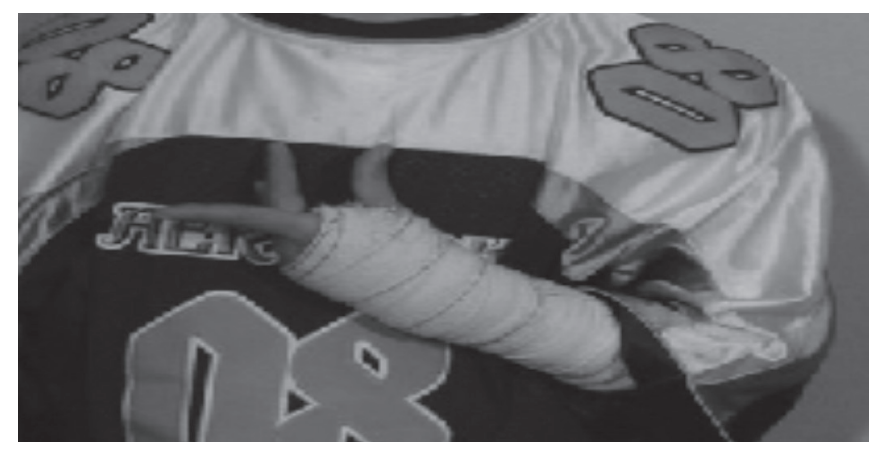

Fuente: Archivo Gabinet de Seguretat

El grupo estaba formado por unas veinticinco personas, de las cuales cinco acabaron detenidas por estos hechos. Después del homicidio, se tuvo conocimiento de hasta cinco agresiones como venganza.

\subsection{Crecimiento y expansión}

Durante el año 2006 se detectó un nuevo grupo de la Mara Salvatrucha en la localidad de Castelldefels. Este nuevo grupo no era excesivamente numeroso: estaba formado por treinta a cuarenta miembros (en ese año la Policia de la Generalitat - Mossos d'Esquadra calculaba que entre 1500 y 2000 jóvenes estaban vinculados a bandas o pandillas en Cataluña). Su conflictividad tampoco era excesiva, aunque se hizo notar en la localidad y aparecieron bastantes pintadas, no tanto en los alrededores de sus puntos de reunión, sino en una estación de tren y sus cercanías.

Durante el año 2007 también se detectó un acercamiento de algunos miembros a la ciudad de Barcelona, con grupos de cuatro o cinco jóvenes, que se identificaban como movimientos previos al establecimiento de una clica en esta ciudad.

Los incidentes principales en que participaron, durante estos dos años, tuvieron que ver con el ocio nocturno, sucedieron en el entorno de discotecas o en las cercanías de estaciones de medios de transporte después de los horarios de cierre de los locales. También se tuvo constancia de alguna pelea con los Black Panthers por intentar implantar, estos últimos, un capítulo en esta localidad. 
Además de la actividad del grupo y de la de sus miembros en particular, poco a poco se fue detectando la presencia en Cataluña de otras personas vinculadas con las maras. Esta detección se realizó a partir de la localización de algún detenido que presentaba tatuajes que lo asociaban con la MS. A partir de aquel momento se prestó mayor atención a los detenidos de nacionalidades centro y norteamericanas. Poco a poco, se identificaron algunas personas, aunque en la mayoría de los casos, los motivos de detención eran ajenos a los grupos y las zonas de residencia; también distaban de los lugares de influencia del grupo establecido en Cataluña. Así, se estableció que no había intención de crear o replicar la actividad de las maras.

Durante el resto del año 2008, la policía catalana calculaba que podía haber unos sesenta jóvenes vinculados con la MS y otros tanto con el B18. El número de incidentes aumentaba y eran más los hechos vinculados con la MS que con el B18, aunque, como ya se ha explicado, incidente más relevante tuvo que ver con este segundo grupo.

El hecho más grave vinculado con la MS durante 2008 fue una agresión con arma blanca (un cuchillo de $12 \mathrm{~cm}$ ) después de una de sus reuniones. Las víctimas fueron dos menores y se detuvo a una persona.

\section{Foto 7.}

\section{Pintada de la MS localizada en las cercanías de uno de sus puntos de reunión en Barcelona}

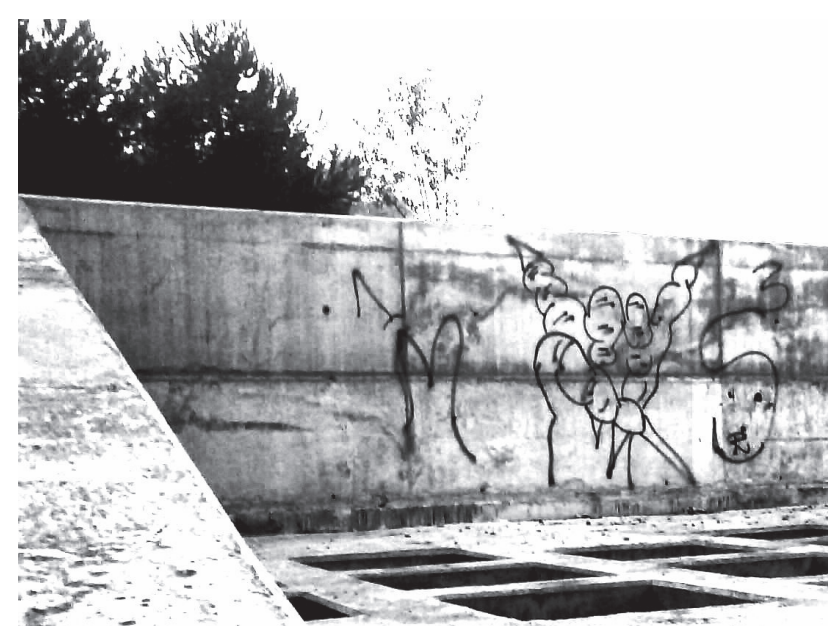

Fuente: Archivo Gabinet de Seguretat.

En ese año se constató la formación de un capítulo estable de la MS en la ciudad de Barcelona y también se detectaron conatos de implantación en algún municipio de la provincia de Tarragona, aunque sin llegar a formar ninguna clica. 
Pese al aumento del número de miembros, el riesgo que suponían estos grupos seguía siendo bajo. La mayoría de los miembros eran muy jóvenes (entre 13 y 16 años) y se habían incorporado al grupo ya en Cataluña, por lo tanto no tenían experiencia previa y desconocían las dinámicas más violentas que se producían en el continente americano. No obstante, el homicidio vinculado con el B18 a principios de año reforzaba la idea de seguir con atención su evolución.

Durante el primer semestre de 2009 la preocupación sobre la MS volvió a aumentar en los alrededores de la ciudad de Barcelona, ya que en algunos barrios de la ciudad y en la localidad limítrofe de l'Hospitalet de Llobregat, aparecieron pintadas más grandes y elaboradas, algunas de ellas incorporaban el número 503, prefijo telefónico de El Salvador. Esto hacía pensar en una mayor presencia de salvadoreños en el grupo y, en consecuencia, en un mayor riesgo de vinculación del grupo con El Salvador, por lo que el nivel de violencia de los miembros podía ser superior. Algunas de estas pintadas se localizaban en el interior de un centro educativo. Paralelamente, se produjo un aumento de la identificación de jóvenes con armas blancas (cuchillos) en las cercanías de estos centros educativos. Esto era un indicador de la juventud de algunos de los miembros.

En Barcelona y sus alrededores, aumentó el número de incidentes durante este año, generalmente peleas los fines de semana, vinculadas con centros de ocio. Puntualmente se detectó algún incidente con la participación de miembros de la MS, por un lado, y del B18, por el otro, el más grave de los cuales fue una agresión con arma blanca.

Aunque en el año 2009 no hubo muertes relacionadas ni con la MS ni con B18, sí se cometieron cinco homicidios vinculados con otros grupos (Ñetas, Trinitarios, Bloods, entre otros), en peleas tumultuarias, por discusiones e, incluso, por cuestiones internas en uno de estos grupos. En la mayor parte de los enfrentamientos se utilizaron objetos contundentes o armas blancas, cuya lesividad es menor, aunque los ingresos hospitalarios de participantes en estas peleas son habituales.

En Girona, hubo nuevos enfrentamientos en la misma discoteca donde el año anterior se había cometido el asesinato, en algunos de los cuales participaron personas vinculadas al grupo del B18 existente en esta ciudad. Pese a que en una ocasión sí se denunció la utilización de un arma de fuego, esta fue únicamente detonadora.

Uno de los factores que motivó este aumento de la conflictividad fue que las dos pandillas mayoritarias en Cataluña, Latin Kings y Ñetas, después de unos años de reducción de la violencia, intentaron ganar terreno, aunque sus liderazgos todavía eran débiles. Esto provocó algunos acercamientos entre grupos. Teniendo en cuenta que Latin Kings siempre fue el grupo 
más numeroso en Cataluña, desde la aparición de la MS se detectaron acercamientos de esta agrupación con los Ñetas para sumar fuerzas y enfrentarse a los Latin Kings. Por otra parte, en Barcelona se había detectado algún intento de acercamiento del B18 a los Latin Kings, en este caso motivado por la rivalidad de ambos con la MS.

El aumento en la conflictividad suponía una retroalimentación en los grupos, ya que cada vez existían más causas de venganzas y reacciones a agresiones previas, lo cual podía derivar en el recurso a armas de fuego (que hasta aquel momento solo habían hecho presencia de manera muy puntual). Además, esto suponía también un incremento de la percepción de inseguridad por parte de la ciudadanía (más adelante se analizarán algunas cuestiones relacionadas con los medios de comunicación) así como un incremento del riesgo en las intervenciones policiales.

Fotos 8 y 9.

Pintadas del Barrio 18 localizadas cerca de uno de sus puntos de reunión en Barcelona
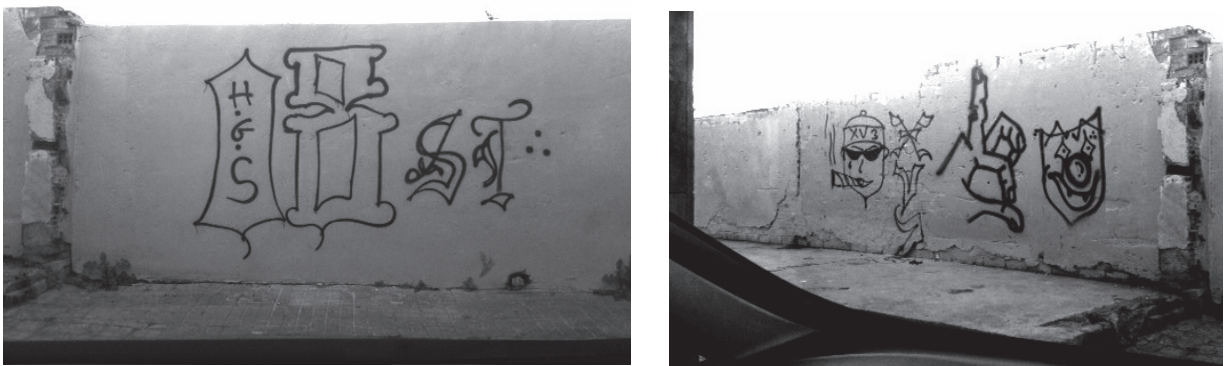

Archivo Gabinet de Seguretat.

En l'Hospitalet de Llobregat se detectó la presencia de una clica del Barrio 18 de unos veinte miembros, entre los cuales había salvadoreños y hondureños, aunque predominaban los de otras nacionalidades, incluidas una chica ucraniana y otra marroquí. Este grupo empezó a realizar ataques a otros grupos, especialmente a la MS. Esto coincide con un cambio de liderazgo y con algunas informaciones que apuntaban a la visita de miembros de Los Ángeles de este mismo grupo para dirigir o dar instrucciones a las clicas en Cataluña.

El segundo homicidio vinculado con maras en Cataluña sucedió en diciembre de 2010. Un miembro de la Mara Salvatrucha, de apenas 14 años, en un parque de Barcelona agredió con un arma blanca a un miembro de Latin Kings, de 17 años de edad. Pese a encontrarse muy cerca de un hospital, los sanitarios no pudieron hacer nada por salvar la vida del joven. El autor de los hechos se refugió en un bar, por miedo a los amigos de la víctima que lo persiguieron, y allí fue detenido por la policía. 


\subsection{Situación actual}

En 2011, según datos de la Policia de la Generalitat - Mossos d'Esquadra, los miembros de la MS eran aproximadamente 175, cifra cercana a los 200 miembros que podrían estar vinculados, en total, en sus diversas clicas.

Entre 2012 y 2015, la totalidad de los incidentes que han protagonizado han estado vinculados a su rivalidad con Latin Kings. Más de la mitad de estos hechos han tenido lugar en diversos barrios de Barcelona. En muchos casos se ha tratado de peleas y caídas ${ }^{5}$, en las que se producen agresiones con objetos contundentes o armas blancas. Aunque las lesiones provocadas, en algunos casos han podido revestir cierta gravedad, no se ha vuelto a dar otro homicidio vinculado con maras en Cataluña.

Una de estas agresiones tuvo lugar en abril de 2012 y estuvo indirectamente vinculado con maras. Unos miembros de los Trinitarios marcaron con un cuchillo la espalda de un miembro que pretendía abandonar el grupo, haciéndole "una herida superficial profunda en la zona de la espalda en forma de X de $50 \mathrm{~cm}$ de altura que precisó sutura con 83 grapas". Según consta en la sentencia judicial, la víctima, de origen peruano, había decidido abandonar la banda, "a la vez que comenzó a frecuentar con más intensidad a otras personas... que pertenecían a la 'MS13, Mara Salvatrucha'" ("Sentencia 337/2014", 2014).

Las estructuras de estas clicas no siempre han sido excesivamente fuertes ni homogéneas. En algunos casos, las actividades de estas clicas estaban muy vinculadas con las actividades de sus miembros o de algunos de sus líderes. En consecuencia, al ser estos detenidos y pasar a cumplir sus respectivas condenas, el nivel de conflictividad del resto del grupo se reducía o llegaba a desaparecer.

En la actualidad, la policía catalana considera que aproximadamente 200 jóvenes forman parte de la MS en Cataluña, con clicas en cuatro municipios diferentes. La mayoría de sus miembros son originarios de naciones latinoamericanas; aunque considerados por país, la mayor parte son españoles; el segundo colectivo en importancia es el ecuatoriano. Únicamente se contabilizan 13 hondureños y 5 salvadoreños. Aunque minoritarios, también se habían vinculado a este grupo jóvenes europeos, asiáticos y africanos.

Por edades, la mayoría de los miembros tienen entre 19 y 25 años, pese a que la horquilla de edades oscila entre 16 y 44 años, con 17 miembros mayores de 30 años. 
La actividad del B18 en los últimos años ha descendido bastante y únicamente se tiene constancia de dos incidentes en 2012, cinco en 2013 y uno en 2014, la gran mayoría en relación con Latin Kings, todos de poca importancia.

En 2013 se contabilizaron 124 miembros del B18. Mientras en la MS apenas el $23 \%$ de los miembros tenían más de 25 años, en B18 suponían el $44 \%$. La edad de sus miembros puede haber sido un factor clave para la desarticulación de las clicas. Por otra parte, la composición por países también difería de la MS. En este caso sí había una mayoría de centroamericanos, 58 hondureños y 6 salvadoreños, aunque también había presencia de españoles, de otros países latinoamericanos y algún asiático o africano. En la actualidad se considera que no hay activa ninguna clica del Barrio 18 en Cataluña, pues en los últimos años han dejado de actuar como grupo. Sin embargo, algunos de sus miembros han cometido algún hecho delictivo o se mueven en el entorno de algún otro grupo juvenil.

\section{Maras en el resto de España}

En marzo de 2014, en una operación a escala nacional, la Guardia Civil detuvo a 35 integrantes de la MS ("La Guardia Civil", 2014), 15 de ellos en Cataluña. Esta operación puso fin a una investigación por el intento de asesinato, en el verano de 2012, de un joven miembro de Latin Kings en la localidad de Ibi (Alicante). Además, se publicitó como la primera gran actuación contra este grupo en España, ya que las detenciones y los registros domiciliarios se realizaron en cinco provincias (Alicante, Madrid, Barcelona, Girona y Tarragona).

A los detenidos se les imputaban, entre otros hechos, delitos de organización criminal, delitos contra la salud pública, y robos con violencia e intimidación. En los registros se intervinieron armas blancas, pequeñas cantidades de droga y armas de fuego simuladas.

Además de los delitos, los investigadores argumentaban que el grupo pretendía establecer una base para el blanqueo de dinero proveniente de los beneficios ilícitos del grupo en otros países. Recientemente, también se ha sabido que uno de los detonantes de esta operación pudo ser la emisión de un reportaje televisivo en España sobre la situación en las cárceles salvadoreñas. En dicho reportaje, titulado Encarcelados, ${ }^{6}$ uno de los miembros de la MS que fue entrevistado dijo que había estado a punto de viajar a España y que otros compañeros suyos ya lo habían hecho. Después de la emisión de dicho programa, el periodista que lo conducía, Jalis de la Serna, dijo que fue llamado por los servicios de inteligencia 
española para interesarse por lo que había conocido en el interior de aquella prisión, y que le habían comentado que durante y después de su emisión se habían detectado llamadas entre El Salvador y España, supuestamente entre miembros de estas pandillas ${ }^{7}$.

Un incidente similar al de verano de 2011 tuvo lugar en Madrid, en otoño de 2011, cuando ocho salvadoreños atacaron a tres jóvenes a la salida de la discoteca Gran Charango la noche del 6 de noviembre de ese año. Según se considera probado en la sentencia de la Audiencia Provincial de Madrid, de 7 de febrero de 2013, los acusados se dirigieron hacia una de las víctimas, la acorralaron y le dieron todo tipo de golpes y patadas en el cuerpo y en la cabeza, sin detenerse cuando había perdido la conciencia. En la investigación de los hechos se supo que algunos de los agresores habían sido identificados como miembros de la MS en Madrid; finalmente, dos de ellos fueron condenados por tentativa de asesinato.

En el Estado español han estado vigentes dos instrucciones de la Secretaría de Estado de Seguridad en las que se implanta y se impulsa un "Plan de actuación y coordinación policial contra grupos organizados y violentos de carácter juvenil". En estas instrucciones, se plantea un abordaje similar para los grupos juveniles de extrema derecha, de extrema izquierda y de origen latino.

De la misma manera que ha pasado en Cataluña, los incidentes relacionados con maras han sido menos que los vinculados con otros grupos más numerosos, especialmente Latin Kings y Ñetas, principalmente por la aparición más tardía y por el menor número de miembros de las maras.

A principios de 2015, la delegada del Gobierno español en Madrid, Cristina Cifuentes, anunció que aplicará la Ley de Extranjería española (Ley Orgánica, 2000) a 34 cabecillas de bandas juveniles ("Cifuentes impulsa", 2015), entre los cuales se encuentran dos miembros de maras, y estudia aplicarla a 94 pandilleros más. Las consecuencias de esta medida son la revocación de la nacionalidad adquirida, la anulación del permiso de residencia o la expulsión del territorio nacional.

Hay que destacar que ni la Mara Salvatrucha ni el Barrio 18 han sido declarados organizaciones ilegales en España ni en Cataluña. Solo una facción de los Latin Kings ha sido declarada asociación ilícita por lo cual se ha ordenado su disolución ${ }^{8}$. En las sentencias existentes sobre la MS

7 Estas declaraciones las realizó en otro reportaje emitido por la misma cadena de televisión, el programa Equipo de investigación (Desterrados, 2015).

8 La Audiencia Provincial de Madrid (sección 15. ${ }^{\circledR}$ ) dictó el 7 de febrero de 2011 una sentencia en que acordaba "la disolución de la Sagrada Tribu América Spain (STAS) de la Todopoderosa Nación de los Reyes y Reinas Latinos (Almighty Latin Kings \& Queens Nation, ALKQN) en lo que respecta a la sección o "Reino" establecido en la Comunidad Autónoma de Madrid (Reino Inca)". Dicha sentencia fue confirmada por la Sala de lo Penal del Tribunal Supremo en sentencia núm. 693/2012, de 19 de julio de 2012. 
y el B18, se reconoce la existencia del grupo y, en algunas ocasiones, se ha condenado a miembros suyos por asociación ilícita o por organización criminal.

Según un censo de grupos de origen latino en la Comunidad de Madrid (Sánchez-Mariscal, 2012) en el segundo semestre de 2011 se habían identificado 78 grupos, 60 de los cuales pertenecían a Latin King, Ñetas, Dominican Don't Play, Forty Two y Trinitarios, y los 18 restantes correspondían a otras diez agrupaciones. Solo uno de estos grupos estaba vinculado a la Mara Salvatrucha. Esta información hace referencia al ámbito de competencia de la Guardia Civil en esta comunidad, que no incluye la capital.

La Fiscalía española mencionaba en su informe sobre los hechos instruidos en 2011, cuatro casos de tentativas de asesinato $u$ homicidio en que los autores, menores de edad, estaban vinculados con la Mara Salvatrucha. Tres de esos hechos habían sucedido en Barcelona y el otro en Madrid. El informe destaca que "se trata de agresiones sorpresivas y muy violentas, protagonizadas por jóvenes ecuatorianos y peruanos en las que utilizan navajas o machetes" (Pozo, Gallego, Vicente y Pérez, 2013, p. 150; Memoria de la Fiscalía del Estado 2012, p. 937). No obstante, en las memorias de los siguientes años (sobre datos de 2012, 2013 y 2014), la referencia a las bandas se hace sin mención específica de las maras. La mayoría de los hechos relacionados con bandas son referidos por la Fiscalía de Barcelona. Hay que tener en cuenta que la memoria la elabora la Fiscalía General del Estado a partir de la información proporcionada, y seleccionada, por las diferentes fiscalías provinciales o autonómicas; por lo tanto, el hecho de que no se expliciten casos vinculados con bandas o pandillas en otras localidades puede ser, mayoritariamente, porque no se han producido, pero puntualmente también puede darse el caso que no se hayan comunicado.

Igual que ha pasado en Cataluña, no todos los mareros que han llegado a otras comunidades de España se han mantenido activos dentro de sus grupos. Un caso destacable es el de W., guatemalteco, que de los 10 a los 23 años fue miembro de la MS en su país. Emigró a España huyendo de la situación en Guatemala, y se desempeña como educador de calle en Madrid, donde trabaja con jóvenes miembros de bandas ${ }^{9}$.

9 Explica su experiencia en un encuentro en el Instituto sobre Globalización, Cultura y Movilidad de la Universidad de Naciones Unidas, con sede en Barcelona, en el contexto de un encuentro sobre jóvenes latinos miembros de grupos juveniles ("Buscando Respeto", 2013). 


\section{Mara Salvatrucha en Italia}

Más allá de las fronteras españolas, también se ha podido constatar la existencia de maras en Italia. Bugli y Conte (2010) destacan que desde 2008 en Milán hay jóvenes que integraron dos grupos de Mara Salvatrucha o MS13 y de la Mara 18, "una presencia que, en un primer momento silenciosa y poco visible, en el último tiempo ha llegado a ser particularmente molesta". La Polizia di Stato detuvo en diferentes ciudades de la región de Lombardía, entre ellas Milán, a 24 miembros de la MS, de entre 17 y 36 años, acusados de asociación para delinquir, robo, tenencia de armas blancas y objetos contundentes, lesiones y agresiones físicas. Entre 2011 y 2013 se habían producido otras tres actuaciones con arrestos de pandilleros de diversos grupos, entre los cuales figuraban miembros de la MS ("Baby gang", 2011; "Milano", 2012; "Droga", 2013; "Rapine", 2013).

\section{Las maras en los medios de comunicación españoles}

Desde la aparición de las bandas juveniles en España, los medios de comunicación han sentido especial atracción por las noticias y hechos relacionados con ellas. No han pasado por alto la violencia característica de la actividad de las maras en Centroamérica y en los Estados Unidos y no la han dejado de utilizar como reclamo para sus noticias.

Así, en el año 2005 se había podido comprobar cómo en un debate sobre Latin Kings y Ñetas se utilizaban de fondo imágenes de brincados de las maras10.

En otros casos, la premura en la presentación de la información provocó errores como el comentado anteriormente, de 2005, cuando unos hechos cometidos por miembros del primer grupo de la MS presente en Barcelona fueron atribuidos a Latin Kings.

No obstante, la situación más habitual ha sido ilustrar las noticias relacionadas con la MS (en los medios de comunicación apenas han aparecido noticias de las acciones del Barrio 18 en Cataluña) con imágenes de estos grupos en El Salvador. El efecto provocado era aumentar la percepción de una mayor peligrosidad de los grupos, además de inducir a pensar que las conexiones entre uno y otro lado del Atlántico eran más fuertes de las realmente existentes.

Los miembros de los grupos también han sido conscientes de la función desempeñada por los medios de comunicación y los han utilizado como

10 El contenido de aquel programa no está accesible a través de internet, y la única referencia que existe es la noticia previa a su emisión ("Las bandas", 2005). 
altavoz, incluso para dar mensajes contradictorios. En septiembre de 2010, solo con dos días de diferencia aparecieron noticias contradictorias relacionadas con el grupo de la MS ubicado en l'Hospitalet de Llobregat.

El día 15 de septiembre aparecía en El Periódico de Cataluña (Placer, 2010) una noticia con el siguiente titular: "La banda Mara 13 organiza colectas para comprar armas en L'Hospitalet". El artículo destacaba la relación que existía con "el fundador del grupo en Honduras" y aunque mantenía que llevaban pistolas a las peleas, también decían que el pago semanal que realizaban los miembros al grupo, 5 euros semanales, tenía por objetivo la compra de armas blancas y pistolas. La fuente de la noticia eran los mismos miembros del grupo, que no dudaron en posar para los periodistas junto a pintadas y haciendo con las manos simbología de los grupos, eso sí, ocultando sus rostros, en algunos casos con camisetas, pañuelos y gorras y en otros poniéndose de espaldas.

Solo una semana más tarde, el 22 de septiembre, una noticia de la televisión pública española comentaba la preocupación policial por el posible aumento del recurso a las armas por parte de los grupos juveniles y recogía unas declaraciones en las que un miembro de MS de l'Hospitalet decía "¿Y para qué armas si se puede defender con los puños uno? Y si ya es un problema grande ya uno sabe cómo se las tiene que arreglar" (Espona, 2010).

Este seguimiento de los medios también ha quedado reflejado en los reportajes sobre bandas y prisiones salvadoreñas explicados en el apartado 5 (ver notas al pie 5 y 6 ).

Mención aparte merece la vinculación que algunas personas han intentado establecer entre las maras y la organización terrorista ETA. El periódico La Razón publicaba en verano de 2013 (Echagüe y Herrero, 2013) la noticia sobre un informe del Gobierno al que habían tenido acceso y que alertaba sobre la presencia de maras en España, si bien se consideraba que se estaban tomando medidas necesarias para evitar su crecimiento. No obstante, el artículo no merecería mayor atención si no fuera porque recogía la opinión de la socióloga argentina Laura Etcharren (2010) quien considera que existen lazos entre las maras y grupos terroristas como ETA y Al Qaeda. Aunque la socióloga no habla estrictamente de maras sino de "narcomaras" -un concepto más difuso que el de maras centroamericanas-, el punto de vista del autor es que esta afirmación se realiza sin ninguna base documental ni hecho probado, por lo tanto no se trata más que de meras especulaciones.

El punto de vista parece diametralmente opuesto cuando la información la proporcionan periodistas acostumbrados a informar de las maras en Centroamérica. Así, el artículo "La pandilla que se ahogó en el océano" 
(Sanz, 2013), publicado en el periódico digital salvadoreño El Faro, sin quitar gravedad a hechos cometidos por las maras y sin obviar el riesgo que supondría la implantación de las maras en España, pone el énfasis en las diferencias entre estos grupos a uno y otro lado del Atlántico.

\section{Valoración final}

Uno de los mayores riesgos asociados con la aparición de los primeros grupos juveniles de origen americano en Cataluña era la posibilidad de que, entre ellos, llegaran y se implantaran las maras y reprodujeran las dinámicas de violencia que tienen en el continente americano. Después de ver su evolución en estos últimos diez años, este riesgo no se ha llegado a materializar, como mínimo, en toda su dimensión.

El primer factor que puede haber contribuido es la composición de los flujos migratorios. Las pandillas de Latin Kings y Ñetas aparecieron con una primera oleada de migrantes ecuatorianos, y Trinitarios y Black Panthers se formaron con la llegada de dominicanos. Los primeros grupos de maras surgieron cuando los colectivos centroamericanos eran muy minoritarios en Cataluña, y los grupos más consolidados han estado vinculados con la presencia de personas de nacionalidad hondureña, colectivo mucho más pequeño que los anteriores. Así, la composición de las maras ha sido más heterogénea, con jóvenes de múltiples nacionalidades y, por tanto, con una menor experiencia directa o indirecta de lo que las maras representan en Centroamérica, y con menor cohesión dentro del grupo. De la misma manera, jóvenes centroamericanos se han incorporado a otros grupos, lo que, indirectamente, puede haber disminuido el número de posibles candidatos a incorporarse a las maras.

No se han generalizado las dinámicas de violencia y venganza. La rápida respuesta por parte del sistema penal (policía, judicatura y prisiones) ha evitado que los hechos delictivos quedaran sin respuesta, factor que aumenta la necesidad de venganza de los grupos. Además, cuando estas se han dado, también se ha actuado contra aquellos que cometían nuevas agresiones.

El conocimiento previo de las dinámicas propias de los grupos, así como su seguimiento también ha contribuido a evitar una mayor implantación de las maras. El control de los grupos y el conocimiento de los miembros suponen una mayor facilidad para identificar a los autores cuando se dan hechos delictivos. Además, al tener conocimiento de las agresiones, también se han realizado labores preventivas para evitar reacciones o venganzas, rompiendo, de esta manera, en la mayoría de los casos, las espirales de violencia. 
La menor conflictividad social y los menores niveles de violencia en la sociedad también han tenido un peso importante. Como se ha visto, casi la totalidad de los hechos vinculados con los grupos han sido realizados con objetos contundentes y armas blancas, lo cual supone que el riesgo para la vida de las personas implicadas siempre ha sido menor. 


\section{Bibliografía}

1. Baby gang, arrestati 2 minori per 11 rapine De Corato: "Bene ha fatto Comune a investire 34 milioni di euro per cintura sicurezza con commissariati e stazioni carabinieri nelle periferie" (2 de marzo de 2011). Milano. Recuperado de http://www.comune.milano.it/dseserver/WebCity/comunicati.nsf/ WEBAll/CD501A5AB5B27CD2C. 125784700525B64?opendocument

2. Bugli, V. y Conte, M. (2010). Giovani latinos e gruppi di strada nella metropoli milanese. En Queirolo Palmas, Atlantico latino. Gang giovanili e culture transnazionali. Roma: Carocci.

3. Buscando Respeto: learning from immigrant youth gang-members. (8 de mayo de 2013). United Nations University. Recuperado de http://gcm.unu.edu/events/archive/other-events/buscando-respeto-learning-from-immigrant-youth-gang-members.html

4. Cifuentes impulsa la aplicación de la Ley de Extranjería a 34 cabecillas de bandas latinas. (25 de febrero de 2015). Secretaría de Estado de Administraciones Públicas. Recuperado de http://www.seap.minhap. gob.es/es/ministerio/delegaciones_ gobierno/delegaciones/madrid/ actualidad/notas_de_prensa/notas/2015/02/2015_02_25.html

5. Detenidos ocho "Latin Kings" por agredir y tirar a la vía a dos pasajeros. (26 de abril de 2005). 20minutos.es. Barcelona Recuperado de http:// cdn.20minutos.es/edicionimpresa/ barcelona/05/04/BARC_26_04_05. pdf
6. Desterrados. (6 de marzo de 2015). LaSexta.com Recuperado de http:// www.lasexta.com/programas/ equipo-investigacion/noticias/puede-acabar-bandas-armadas-espana_2015030400152.html

7. Droga: guerra alle pandillas, 60 arrestati. (19 de marzo de 2013). Polizia di Stato. Recuperado de http://www. poliziadistato.it/articolo/pdf/28667/

8. Encarcelados. (7 de noviembre de 2013). LaSexta.com Recuperado de http://www.lasexta.com/ programas/encarcelados/avan. ces/jalis-serna-viaja-pais-que-decadas-sufrido-violencia-ma. ras_2013110600806.html

9. Echagüe, J. V. y Herrero, B. (11 de agosto de 2013). El Gobierno alerta de un aumento de las maras en España. La Razon. Recuperado de http://www.larazon.es/sociedad/elgobierno-alerta-de-un-aumento-delas-maras-DC3271445\#.Ttt153KU. vAILyJO

10. Espona, C. (22 de septiembre de 2010). La policía ha informado del aumento de bandas latinoamerica. nas en toda España. RTVE. Recuperado de http://www.rtve.es/alacarta/ videos/programa/policia-informado-del-aumento-bandas-latinoamericanas-toda-espana/884056/

11. Etcharren, L. (12 de julio de 2010). Maras en Cataluña. Laura Etcharren. Recuperado de http://soclauraetcharren.blogspot.com.es/2010/07/ maras-en-cataluna.html 
12. Herrero Blanco, S. (2012). PandiIlas en Cataluña: El abordaje desde la Policia de la Generalitat - Mos. sos d'Esquadra. Policía y Seguridad Pública, 2. Recuperado de http://www.ansp.gob.sv/index. php?option=com_phocadownload\&. view $=$ category\&id=2: publicacio nes\&download=125:2012.p\&l. temid $=115 \&$ e $i=8 \mathrm{sJKUdekFI}$. W 1 hAf9i4GABQ \&usg = AFQjC. NEXgHjxko9zQhZQJM4FV_8V. JDEtPQ\&bvm=bv.44158598,d. ZG4\&cad=rja

13. Idescat. (2011). Población residente en el extranjero. Instituto de Estadística de Cataluña. Recuperado de http://www.idescat.cat/ pub $/$ ? id =aec \&n=969\&lang $=e s \&$. $t=2009 \& x=12 \& y=4$

14. Idescat. (2015a). Movimiento natural. Instituto de Estadística de Cataluña. Recuperado de http://www. idescat.cat/es/poblacio/mnp/

15. Idescat. (2015b). Población extranjera. Instituto de Estadística de Cataluña. Recuperado de http:// www.idescat.cat/poblacioestrange$\mathrm{ra} /$ ?lang=es

16. La Guardia Civil detiene a los 35 principales integrantes de la Mara Salvatrucha (MS-13). (25 de marzo de 2014). Guardia Civil. Recuperado de http://www.guardiacivil.es/va/ prensa/noticias/4837.html

17. Las bandas juveniles a debate. (4 de octubre de 2005). RTVE. Recuperado de http://www.rtve.es/ FRONT_SALA_PRENSA/?go=ea. caa4148f48af89730076a6669d. f2169fcb5b71e1aa29da7430766a$31 d 4 f 3 b b a 2 f d a 9 a 42 c f b 69 a 123 f$. ca9c847cc9427
18. Ley Orgánica 4/2000, de 11 de enero, sobre derechos y libertades de los extranjeros en España y su integración social. (2000). Agencia Estatal Boletín Oficial del Estado. Recuperado de http://www.boe.es/ buscar/act.php?id=BOE-A-2000-544

19. Memorias de la Fiscalía General del Estado. (Varios años). Fiscalía General del Estado. Recuperado de_https://www.fiscal.es/fiscal/publico/ ciudadano/documentos/memorias_ fiscalia_general_estado

20. Milano: 25 arrestati per guerra tra gang di sudamericani. (7 de febrero de 2012) Polizia di Stato. Recuperado de http://www.poliziadistato.it/ articolo/pdf/25161/

21. Pardo, G. (13 de enero de 2004). La Mara Salvatrucha. Nuevo instrumento del hampa en la zona centroamericana. Red Voltaire. Recuperado de_http://www.voltairenet.org/article120605.html

22. Placer, D. (15 de septiembre de 2010). La banda Mara 13 organiza colectas para comprar armas en L'Hospitalet. El Periodico. Recuperado de http://www.elperiodico.com/ es/noticias/barcelona/20100915/ banda-mara-organiza-colec. tas-para-comprar-armas-Ihospitalet/479447.shtml

23. Pozo Martínez, A.; Gallego Meseguer, P. A.; Vicente Castro, F.; Pérez Ruiz, M. L. (2013). Spain - National Analysis. En Brutto, S. y Misesso, A. (Eds.) Interaction of different sub. jects towards a strategic common answer concerning juvenile gangs. Verona. Recuperado de http://youthgangs.ejjo.org/sites/default/files/ itaca_-final_report-.pdf 
24. Queirolo Palmas, L. (2013). Gangs Policies: Youth and Migration in Local Contexts. The Case of Madrid and Barcelona. YOUGANG - Project N. IEF 272200. Recuperado de http://www.yougangproject.com/ wp-content/uploads/2012/02/YOU. GANG-informe-final_sp.pdf

25. Rapine, botte e violenze. Presi 24 "Mareros" dell'MS13. (8 de octubre de 2013). poliziadistato.it Recupera. do de http://www.poliziadistato.it/ articolo/pdf/30402/

26. Red para la Infancia y la Adolescencia de El Salvador. (2004). Informe de El Salvador en el marco de la problemática de las "pandillas o ma. ras". Recuperado de _http://www. redlamyc.info/Seguim_Convenc_De. rech_ninio/Coaliciones\%20Naciona. les $\% 20$ de\%20Seguimiento/INFOR. ME\%20ES\%20CIDH.doc

27. Sánchez-Mariscal Arnaiz, D. (2012). Evolución de las bandas juveniles de carácter violento en la Comunidad de Madrid. Instituto Universitario de Investigación sobre Seguridad Inte. rior. Recuperado de http://www.iuisi.es/12_publicaciones/12_2012/ TomollI_Partell_2012.pdf

28. Sanz, J. L. (1 de julio de 2013). La pandilla que se ahogó en el océano. El Faro. Recuperado de http:// www. elfaro.net/es/201306/noti. cias/12563/

29. Sentencia $337 / 2014$ de la Sala de lo Penal de Tribunal Supremo (9 de abril de 2014). Recuperado de http://www.poderjudicial.es/ stfIs/SALA\%20DE\%20PRENSA/ NOTAS\%20DE\%20PRENSA/TS\%20 Penal\%2016-04-2014.pdf
30. Sentencia $693 / 2012$ de la Sala de lo Penal del Tribunal Supremo (19 de julio de 2012). Recuperado de http://www.poderjudicial.es/stfls/ SALA\%20DE\%20PRENSA/NOVEDA. DES/28079120012012100699.pdf 
